\title{
Documentation and Management of Overweight and Obesity in Primary Care
}

\author{
Molly E. Waring, PhD, Mary B. Roberts, MS, Donna R. Parker, ScD, and \\ Charles B. Eaton, MD, MS
}

Purpose: We examined overweight/obesity management in primary care in relation to body mass index (BMI), documentation of weight status, and comorbidities.

Methods: This analysis of baseline data from the Cholesterol Education and Research Trial included 2330 overweight and obese adult primary care patients from southeastern New England. Data were obtained via a telephone interview and abstraction of patients' medical records. BMI $\left(\mathrm{kg} / \mathrm{m}^{2}\right)$ was calculated from measured height and weight. Management of overweight/obesity included advice to lose weight, physical activity recommendations, dietary recommendations, and referral for nutrition counseling.

Results: Documentation of weight status was more common with increasing BMI (13\% of overweight patients, 39\% of mildly obese patients, and $77 \%$ of moderately/severely obese patients). Documentation of overweight/obesity was associated with increased behavioral treatment; the biggest increase was seen for advice to lose weight (odds ratios were 7.2 for overweight patients, 3.3 for patients with mild obesity, and 4.0 for patients with moderate/severe obesity). Although weight-related comorbidities were associated with increased overweight/obesity management at all BMIs, the biggest increase in odds was for patients with moderate/severe obesity.

Conclusions: Documentation of weight management was more common among patients with documented overweight/obesity and with weight-related comorbidities. These insights may help in designing new interventions in primary care settings for overweight and obese patients. ( $\mathrm{J}$ Am Board Fam Med 2009;22:544-552.)

The two-thirds of US adults who are overweight or obese $^{1}$ are at increased risk for hypertension, dyslipidemia, type 2 diabetes, cardiovascular disease, osteoarthritis, sleep apnea, some cancers, depression, and reduced life expectancy. ${ }^{2-6}$ Current practice guidelines recommend that adult primary care patients be screened for overweight and obesity. ${ }^{7,8}$ Primary care physicians reach most segments of the

This article was externally peer reviewed.

Submitted 26 August 2008; revised 29 January 2009; accepted 2 February 2009.

From the Center for Primary Care and Prevention, Memorial Hospital of Rhode Island, Pawtucket (MEW, MBR, DRP, CBE); the Department of Community Health (MEW, DRP, CBE) and the Department of Family Medicine (CBE), Warren Alpert Medical School, Brown University, Providence, RI.

Funding: Data collection was supported by National Heart, Lung and Blood Institute grant 1 R01 HL070804-01: Translating ATPIII Cholesterol Management Guidelines into Primary Care Practice.

Conflict of interest: Dr. Eaton is a member of the National Committee for Quality Assurance's Adult Obesity panel.

Corresponding author: Molly E. Waring, Center of Primary Care and Prevention, $2^{\text {nd }}$ floor, Memorial Hospital of Rhode Island, 111 Brewster Street, Pawtucket, RI 02860 (E-mail: molly_waring@brown.edu). population and their expertise is highly regarded by patients; this places them in a unique position to motivate and counsel overweight or obese patients about the health benefits of moderate weight loss, improved diet, and increased physical activity. ${ }^{9}$ Yet, despite this "epidemic of obesity," there is mounting evidence that many primary care providers are not adequately addressing overweight/obesity. ${ }^{10-20}$

Many studies assessing the recognition and management of obesity in primary care have not differentiated levels of obesity. ${ }^{15-19}$ In addition, few studies included overweight patients; ${ }^{14,15}$ however, there is strong clinical trial evidence that modest weight loss in this group can delay or prevent the development of diabetes, hypertension, and dyslipidemia. ${ }^{21-23}$ In addition, overweight patients with comorbidities have greater mortality risks than those who are obese but have no comorbid conditions. $^{2,6}$ Given the increasing health consequences with increasing body mass index $(\mathrm{BMI})^{17}$ and the benefits of weight loss among overweight individuals, differentiating between overweight and classes of obesity is important to better understand over- 
weight/obesity management in primary care and to better translate evidence-based guidelines into clinical practice. In this study, we examined 2 factors that may influence overweight/obesity management in the primary care setting: (1) documentation of overweight/obesity and (2) the presence of weight-related comorbidities. Understanding current overweight/obesity management practices could inform future education efforts and interventions to promote successful treatment in the primary care setting.

\section{Methods}

This study uses baseline data from the Cholesterol Education and Research Trial, a randomized cluster quality improvement trial testing the effectiveness of translating the Adult Treatment Panel III guidelines into clinical practice. The Memorial Hospital of Rhode Island Institutional Review Board approved the study. Thirty representative, nonacademic primary care practices (15 internal medicine and 15 family practice; 15 group practices and 15 solo practices) were recruited from Rhode Island and Massachusetts. Patients eligible for the Cholesterol Education and Research Trial (aged 20-80 years; spoke English; had at least one physician visit during the past 2 years) received letters signed by their physicians inviting them to participate in the study. A random sample of 20 to 120 patients per practice was selected from patients who provided informed consent. Participants completed a short, computer-assisted telephone interview and research assistants abstracted medical records from May 25, 2004, through August 18, 2005. After excluding patients who were pregnant $(\mathrm{n}=18)$, missing weight $(\mathrm{n}=83)$ or height $(\mathrm{n}=$ 770 ), or who were underweight (BMI $<18.5 \mathrm{~kg} / \mathrm{m}^{2}$; $\mathrm{n}=41)$ or normal weight $\left(18.5 \mathrm{~kg} / \mathrm{m}^{2} \leq \mathrm{BMI}<25\right.$ $\left.\mathrm{kg} / \mathrm{m}^{2} ; \mathrm{n}=1017\right)$, the present sample included 2330 overweight or obese primary care patients.

BMI was calculated from the most recent weight and height recorded in the medical record. Patients were classified as overweight $\left(25 \mathrm{~kg} / \mathrm{m}^{2} \leq \mathrm{BMI}<\right.$ $\left.30 \mathrm{~kg} / \mathrm{m}^{2}\right)$, mildly obese $\left(30 \mathrm{~kg} / \mathrm{m}^{2} \leq \mathrm{BMI}<35\right.$ $\left.\mathrm{kg} / \mathrm{m}^{2}\right)$, or moderately/severely obese $\left(35 \mathrm{~kg} / \mathrm{m}^{2} \leq\right.$ $\mathrm{BMI}){ }^{7}$ Because primary care physicians may record overweight even when the patient is clinically obese, we considered documentation of either overweight or obesity. Documentation included information abstracted from the patient's problem list and/or any notation indicating the patient's weight status (eg, "patient is obese"). Research assistants reviewed medical records for advice to lose weight, physical activity and dietary recommendations, and referral for nutrition counseling within the previous 2 years. Evidence of physical activity or dietary recommendations included any notation of advice. Documentation of 4 common, weightrelated comorbidities (diabetes, lipid disorders, hypertension, and cardiovascular disease) required the diagnosis or documentation on the problem list and was not based solely on medication use, laboratory data, or blood pressure readings. Diabetes included both type I and type 2 diabetes but excluded gestational diabetes. During the telephone interview, patients reported their date of birth, sex, marital status, education, and smoking status. Patients who reported smoking at least one cigarette during the past month were considered smokers.

We compared the characteristics of patients and measures of overweight/obesity management across degrees of overweight/obesity. We then compared patterns of overweight/obesity management in relation to documentation of overweight/ obesity and presence of weight-related comorbidities, within each group (overweight, mild obesity, and moderate/severe obesity). Next, we estimated odds ratios using generalized linear mixed models with a logit link function to adjust for the clustering of patients within medical practices. ${ }^{24,25} \mathrm{We}$ evaluated each model for confounding by age, sex, smoking status, race/ethnicity, education, and marital status. ${ }^{110-12,15-18}$ Potential confounders that changed the estimate of association by at least $10 \%$ were retained in each model. Models were fit separately for each measure of overweight/obesity management within each weight category. Variables included in each model are indicated in table footnotes. Analyses were conducted with SAS software 9.1.3 for Windows (SAS Institute, Inc., Cary, NC).

\section{Results}

Patients with higher BMIs were, on average, more likely to be women and less likely to be married or cohabitating (Table 1). Documentation of overweight/obesity was more common with increasing BMI. Overweight or obesity was documented in $13 \%$ of overweight patients' charts, $39 \%$ of mildly obese patients' charts, and $77 \%$ of moderately/ severely obese patients' charts (Table $1 ; P<.01$ for 


\begin{tabular}{|c|c|c|c|}
\hline & $\begin{array}{l}\text { Overweight* } \\
(\mathrm{n}=1236)\end{array}$ & $\begin{array}{l}\text { Mild Obesity }{ }^{\dagger} \\
\quad(\mathrm{n}=661)\end{array}$ & $\begin{array}{l}\text { Moderate or Severe } \\
\text { Obesity }^{\ddagger}(\mathrm{n}=433)\end{array}$ \\
\hline Female (\%) & 51 & 54 & 66 \\
\hline Age (mean years [SE]) & $54.5(0.8)$ & $53.9(0.9)$ & $54.7(0.9)$ \\
\hline \multicolumn{4}{|l|}{ Marital status (\%) } \\
\hline Married/cohabitating & 74 & 72 & 62 \\
\hline Single & 11 & 13 & 16 \\
\hline Widowed/divorced/separated & 14 & 14 & 21 \\
\hline Non-Hispanic white (\%) & 94 & 94 & 93 \\
\hline \multicolumn{4}{|l|}{ Education (\%) } \\
\hline$\leq$ High school & 33 & 34 & 39 \\
\hline Technical/junior/some college & 21 & 26 & 24 \\
\hline College graduate & 27 & 24 & 24 \\
\hline Postgraduate/professional degree & 19 & 17 & 13 \\
\hline Current smoker (\%) & 13 & 16 & 15 \\
\hline Overweight or obesity documented (\%) & 13 & 39 & 77 \\
\hline \multicolumn{4}{|l|}{ Comorbidities (\%) } \\
\hline Diabetes & 8 & 14 & 26 \\
\hline Lipid disorder & 61 & 63 & 68 \\
\hline Hypertension & 42 & 56 & 69 \\
\hline Cardiovascular disease & 10 & 11 & 15 \\
\hline At least one comorbidity (\%) & 71 & 78 & 88 \\
\hline
\end{tabular}

$* 25 \mathrm{~kg} / \mathrm{m}^{2} \leq$ body mass index (BMI) $<30 \mathrm{~kg} / \mathrm{m}^{2}$.

${ }^{+} 30 \mathrm{~kg} / \mathrm{m}^{2} \leq \mathrm{BMI}<35 \mathrm{~kg} / \mathrm{m}^{2}$.

${ }^{\ddagger} 35 \mathrm{~kg} / \mathrm{m}^{2} \leq$ BMI.

linear trend across BMI categories). The prevalence of each comorbidity increased with increasing $\mathrm{BMI}$, as did the proportion of patients with at least one of these comorbid conditions (Table 1). All 4 measures of overweight/obesity management increased with increasing degree of overweight/obesity $(P<.01$ for linear trend for each measure).

All 4 measures of overweight/obesity management were more common among those with higher BMIs (Figure 1). Although physical activity and diet recommendations were common among all patients, for only patients with moderate/severe obesity that was documented by their physician was the prevalence of advice to lose weight more than $50 \%$; less than a quarter of overweight and obese patients received referrals for nutrition counseling (Figure 1). We found increased odds of overweight/obesity management in relation to documentation of overweight/obesity within each BMI category; odds ratios ranged from 1.9 to 7.2 , depending on the measure of management and BMI category (Table 2). Documentation of overweight/ obesity in the progress note or problem list had a much greater impact on advice to lose weight among overweight patients compared with those with mild or moderate/severe obesity (odds ratios, 7.2 vs 3.3 and 4.0; Table 2).

A similar pattern of overweight/obesity management practices was observed for overweight and obese primary care patients in relation to the presence of weight-related comorbidities (Figure 2). We found increased odds of overweight/obesity management in relation to the presence of weightrelated comorbidities within each BMI category; odds ratios ranged from 1.2 to 4.8 , depending on the measure of management and BMI category (Table 3). Although weight-related comorbidities were associated with a similar increase in odds of referrals for nutrition counseling for patients with differing levels of overweight/obesity, weight-related comorbidities had a greater impact on advice to lose weight, physical activity recommendations, and diet recommendations among patients with moderate/severe obesity (Table 3).

\section{Discussion}

In this study of overweight and obese primary care patients, we found that documentation of weight 

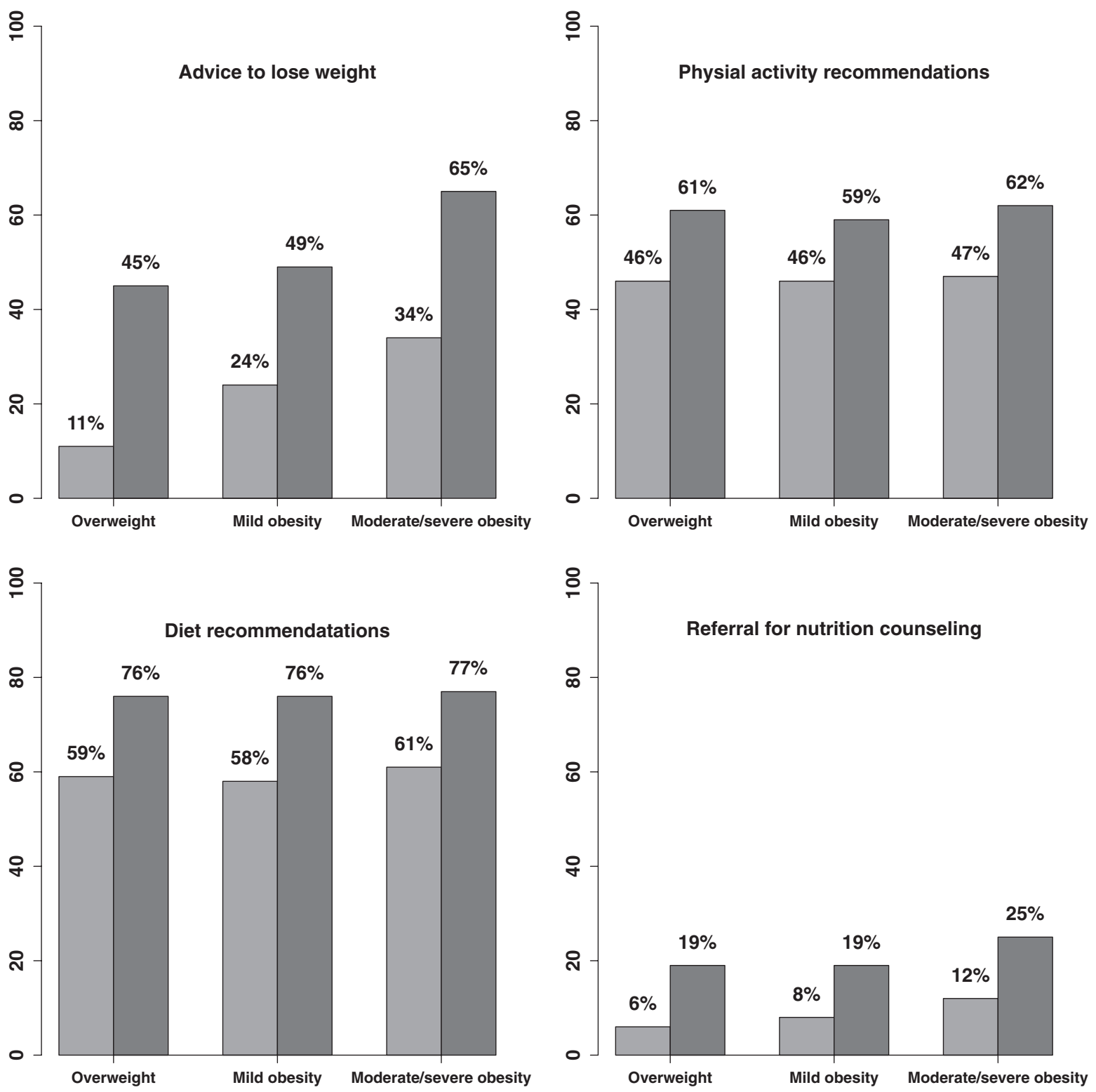

Figure 1. Management of overweight/obesity by documentation of overweight/obesity and degree of overweight/ obesity. The light gray bars represent patients without documented overweight/obesity; the dark gray bars represent patients with documented overweight/obesity.

status and behavioral interventions were more common among patients with increasing BMIs and that overweight/obesity management occurred more frequently among patients with documented weight status and those with weight-related comorbidities.

Our study confirms previous findings that overweight/obesity management occurs more frequently with increasing $\mathrm{BMI}^{10,12,16-19}$ and the rates of physical activity and dietary recommendations in our population were similar to those found in previous studies. ${ }^{13,19,26}$ In the present study, referral for nutrition counseling was the least common treatment strategy. Patients with moderate/severe obesity and weight-related comorbidities (24\%) were the most likely to receive a referral for nutrition counseling.

Behavioral interventions were more frequent among patients with documented overweight or obesity. ${ }^{10,11,14,16,18,27}$ Documentation of overweight/obesity was associated with similarly increased odds of physical activity and dietary recommendations and referrals for nutrition counseling across degrees of overweight/obesity. However, 
Table 2. Management of Overweight/Obesity among Primary Care Patients by Documentation of Overweight/Obesity and Degree of Overweight/Obesity*

\begin{tabular}{|c|c|c|c|c|}
\hline & $\begin{array}{l}\text { Documentation of } \\
\text { Overweight and/or Obesity }\end{array}$ & Overweight & $\begin{array}{l}\text { Mild } \\
\text { Obesity }\end{array}$ & $\begin{array}{c}\text { Moderate or } \\
\text { Severe Obesity }\end{array}$ \\
\hline \multirow[t]{2}{*}{ Advise to lose weight } & Yes & $7.2(4.8-10.6)^{\dagger}$ & $3.3(2.3-4.6)$ & $4.0(2.4-6.6)$ \\
\hline & No & (Referent) & (Referent) & (Referent) \\
\hline \multirow[t]{2}{*}{ Physical activity recommendations } & Yes & $2.3(1.5-3.4)$ & $1.9(1.3-2.8)$ & $2.2(1.3-3.7)$ \\
\hline & No & (Referent) & (Referent) & (Referent) \\
\hline \multirow[t]{2}{*}{ Diet recommendations } & Yes & $2.9(1.8-4.7)$ & $3.2(2.1-4.9)$ & $2.5(1.5-4.3)$ \\
\hline & No & (Referent) & (Referent) & (Referent) \\
\hline \multirow[t]{2}{*}{ Referral for nutrition counseling } & Yes & $3.3(2.1-5.4)^{\ddagger}$ & $2.5(1.6-4.0)$ & $2.7(1.4-5.2)^{\S}$ \\
\hline & No & (Referent) & (Referent) & (Referent) \\
\hline
\end{tabular}

*Overweight: $25 \mathrm{~kg} / \mathrm{m}^{2} \leq$ body mass index (BMI) $<30 \mathrm{~kg} / \mathrm{m}^{2}$; mildly obese: $30 \mathrm{~kg} / \mathrm{m}^{2} \leq \mathrm{BMI}<35 \mathrm{~kg} / \mathrm{m}^{2}$; moderately/severely obese: $35 \mathrm{~kg} / \mathrm{m}^{2} \leq \mathrm{BMI}$. All data shown as adjusted odds ratio $(95 \% \mathrm{CI})$.

${ }^{\dagger}$ Adjusted for sex.

${ }^{\ddagger}$ Adjusted for age.

${ }^{\S}$ Adjusted for education.

documentation of overweight/obesity was associated with higher increased odds of advice to lose weight among overweight patients compared with patients with mild or moderate/severe obesity. Because modest weight loss could shift overweight patients into a healthy weight category, perhaps physicians may be more likely to both document overweight and provide weight-loss advice for the subset of overweight patients they believe may successfully achieve weight loss. Alternatively, some overweight patients may initiate conversations about weight with their physicians, leading to both documentation of their weight status and a physician recommendation of weight loss. Although there are multiple potential explanations, this finding suggests that increasing documentation of overweight might lead to increased management activities.

Although those with comorbid conditions may be more likely to receive advice to lose weight, ${ }^{12,15}$ studies have found that only about half of obese patients with comorbidities received advice from their physician to lose weight. ${ }^{11,16}$ We found that, at all levels of overweight/obesity, those with comorbidities were more likely to have documented behavioral interventions for overweight/obesity. ${ }^{10,12,15,17}$ The increase in odds associated with the presence of weight-related comorbidities was greatest for advice to lose weight and physical activity and dietary recommendations. Frequency of lifestyle advice in relation to weight-related comorbidities has not been investigated in such a way by previous studies. $^{14-16}$

This study has several strengths and limitations. We differentiated between mild and moderate/severe obesity and included overweight individuals, which resulted in greater understanding of overweight/obesity management. We were unable to differentiate between moderate and severe obesity because of limited numbers of patients in these weight categories. Although BMI does not differentiate between lean and fat mass, BMI is highly correlated with waist circumference, is similarly related to total and abdominal fat, ${ }^{28}$ and is recommended for the classification of overweight and obesity in adults by national evidence-based clinical guidelines. ${ }^{7,8}$ The primary care providers in this study included general internists and family physicians from a spectrum of practice types. Although many previous studies have assessed management of overweight and obesity from care provided during a single office visit ${ }^{11,29,30}$ or patient self-reports of care, ${ }^{12,16-18}$ we reviewed 2 years of documented care, which better reflects the longitudinal nature of primary care. The design of the chart abstraction limited our ability to establish a temporal relationship between weight status and documentation and management of overweight/obesity. However, in this sample, on average, patients' weight classification did not change over the course of 12 to 18 months (unpublished data). Because this sample comes from southeastern New England and was predominantly non-Hispanic white, our findings 

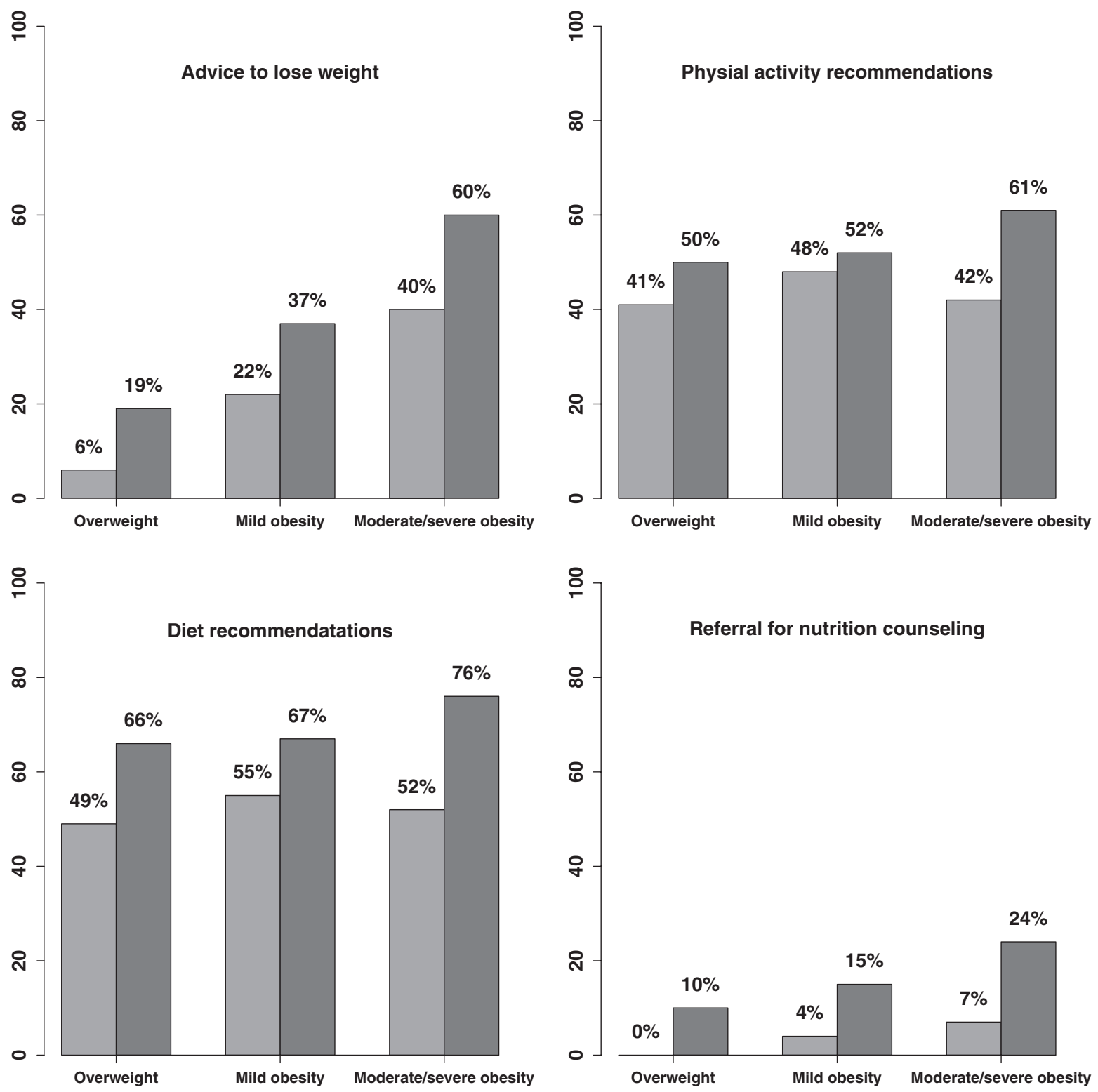

Figure 2. Management of overweight/obesity by presence of at least one weight-related comorbidity and degree of overweight/obesity. The light gray bars represent patients without selected weight-related comorbidities (diabetes, lipid disorders, hypertension, or cardiovascular disease); the dark gray bars represent patients with at least one of these weight-related comorbidities.

may not be generalizable to primary care patients from other regions of the country or of other races/ ethnicities.

A common limitation of data obtained from chart reviews is the potential discrepancy between conversations and the documentation of those conversations. Although documentation of weight status indicates recognition, a lack of documentation does not necessarily imply a lack of recognition. Therefore, it is possible that physicians discussed weight with their patients or made behavioral rec- ommendations but did not document these conversations in the patient's chart. It is unknown whether this likely underestimate occurred differentially across BMI categories. Because practice guidelines suggest lifestyle modifications for the weight-related comorbidities studied, we were unable to determine whether behavioral recommendations were made to manage these health conditions or for weight control. In addition, we were not able to assess whether conversations were initiated by physicians or patients. This is a problem common to 
Table 3. Management of Overweight/Obesity among Primary Care Patients by Presence of At Least One WeightRelated Comorbidity and Degree of Overweight/Obesity*

\begin{tabular}{|c|c|c|c|c|}
\hline & $\begin{array}{l}\text { At Least One Weight- } \\
\text { Related Comorbidity }\end{array}$ & Overweight & $\begin{array}{l}\text { Mild } \\
\text { Obesity }\end{array}$ & $\begin{array}{c}\text { Moderate or Severe } \\
\text { Obesity }\end{array}$ \\
\hline \multirow[t]{2}{*}{ Advice to lose weight } & Yes & $2.3(1.5-3.4)^{\dagger}$ & $2.0(1.4-3.0)$ & $3.4(1.9-6.2)^{\dagger}$ \\
\hline & No & (Referent) & (Referent) & (Referent) \\
\hline \multirow[t]{2}{*}{ Physical activity recommendations } & Yes & $1.5(1.1-1.9)$ & $1.2(0.8-1.7)$ & $2.9(1.5-5.4)^{\dagger}$ \\
\hline & No & (Referent) & (Referent) & (Referent) \\
\hline \multirow[t]{2}{*}{ Dietary recommendations } & Yes & $2.4(1.8-3.2)$ & $2.0(1.3-3.0)$ & $4.8(2.4-9.6)^{\dagger \neq}$ \\
\hline & No & (Referent) & (Referent) & (Referent) \\
\hline \multirow[t]{2}{*}{ Referral for nutrition counseling } & Yes & $3.4(1.8-6.4)^{\dagger}$ & $3.1(1.6-6.1)$ & $3.3(1.4-7.6)$ \\
\hline & No & (Referent) & (Referent) & (Referent) \\
\hline
\end{tabular}

*Overweight: $25 \mathrm{~kg} / \mathrm{m}^{2} \leq$ body mass index $(\mathrm{BMI})<30 \mathrm{~kg} / \mathrm{m}^{2}$; mildly obese: $30 \mathrm{~kg} / \mathrm{m}^{2} \leq \mathrm{BMI}<35 \mathrm{~kg} / \mathrm{m}^{2}$; moderately/severely obese: $35 \mathrm{~kg} / \mathrm{m}^{2} \leq \mathrm{BMI}$. All data shown as adjusted odds ratio $(95 \% \mathrm{CI})$.

${ }^{\dagger}$ Adjusted for age.

${ }^{\ddagger}$ Adjusted for sex.

many studies exploring the management of overweight/obesity in primary care, ${ }^{14,26}$ and there is evidence that both patients and clinicians initiate conversations about weight control. ${ }^{20,31}$

Practice guidelines ${ }^{8}$ recommend more intensive counseling than may be feasible in the context of a primary care visit. Reported challenges in effectively treating obesity in the primary care setting include lack of time, inadequate training on how to counsel patients, lack of insurance reimbursement, patient noncompliance, inadequate teaching materials, and low confidence. ${ }^{17,27,32-35}$ Although some physicians may feel that patients would not want to discuss their weight, many overweight and obese patients feel that their excess weight is unhealthy and would feel comfortable discussing weight with their physician. ${ }^{17,19,30}$

Because primary care providers' advice can have an impact on patients' behavior ${ }^{12,18,26}$ and on patients' confidence and motivation to change their behavior, ${ }^{30}$ there is a need to devise approaches that may help primary care clinicians balance visit constraints and the need for intensive lifestyle counseling to treat overweight and obesity in their patients. Electronic medical records offer the potential for the automatic calculation of BMI at the point of service, which has been found to increase documentation of weight status and treatment in obese patients' charts. ${ }^{36} \mathrm{Web}$ sites can provide patients with tailored and interactive health information. ${ }^{37}$ Some research has found patients to have positive experiences and attitudes with electronic health records and electronic communication with their providers about their care. ${ }^{38}$ Group medical visits facilitated by physicians and other primary care professionals may provide a venue for increased patient education and understanding about their health. Newly implemented group medical visit programs have had positive responses from patients. ${ }^{39,40}$ However, many team-focused approaches may require reformed payment approaches to primary care. ${ }^{41,42}$

In our study, documentation of weight management was more common for patients with documented overweight/obesity and among patients with weight-related comorbidities. Advice to lose weight was documented for a minority of overweight and mildly obese patients, yet these patients may have the greatest chance of obtaining a healthy weight. Triggers or office system approaches may be helpful in the management of overweight/obesity in the primary care setting. Research is needed to explore strategies to help primary care physicians balance time constraints and competing demands to provide the more intensive behavioral interventions needed to combat the obesity epidemic.

We would like to thank the participating practices and the research assistants who conducted the medical record abstractions.

\section{References}

1. Ogden CL, Carroll MD, Curtin LR, McDowell MA, Tabak CJ, Flegal KM. Prevalence of overweight and obesity in the united states, 1999-2004. JAMA 2006; 295:1549-55. 
2. Pi-Sunyer FX. Medical hazards of obesity. Ann Intern Med 1993;119(7 Pt 2):655-60.

3. Hu FB, Manson JE, Stampfer MJ, et al. Diet, lifestyle, and the risk of type 2 diabetes mellitus in women. N Engl J Med 2001;345:790-7.

4. Eckel RH. Obesity and heart disease: a statement for healthcare professionals from the nutrition committee, american heart association. Circulation 1997;96: $3248-50$

5. Onyike CU, Crum RM, Lee HB, Lyketsos CG, Eaton WW. Is obesity associated with major depression? Results from the third national health and nutrition examination survey. Am J Epidemiol 2003; 158:1139-47.

6. Peeters A, Barendregt JJ, WIllekens F, Mackenbach JP, Al Mamun A, Bonneux L. Obesity in adulthood and its consequences for life expectancy: a life-table analysis. Ann Intern Med 2003;138:24-32.

7. National Institutes of Health. Clinical Guidelines on the Identification, Evaluation, and Treatment of Overweight and Obesity in Adults-The Evidence Report. Baton Rouge, LA: North American Association for the Study of Obesity, 1998;6(Suppl 2):51.

8. US Preventive Services Task Force. Screening for obesity in adults: recommendations and rationale. Ann Intern Med 2003;139:930-2.

9. Hiddink GJ, Hautvast JG, van Woerkum CM, Fieren CJ, Van't Hof MA. Consumers' expectations about nutrition guidance: the importance of primary care physicians. Am J Clin Nutr 1997;65(6 Suppl): 1974S-9S.

10. Simkin-Silverman LR, Gleason KA, King WC, et al. Predictors of weight control advice in primary care practices: patient health and psychosocial characteristics. Prev Med 2005;40:71-82.

11. Stafford RS, Farhat JH, Misra B, Schoenfeld DA. National patterns of physician activities related to obesity management. Arch Fam Med 2000;9:631-8.

12. Galuska DA, Will JC, Serdula MK, Ford ES. Are health care professionals advising obese patients to lose weight? JAMA 1999;282:1576-8.

13. Wadden TA, Anderson DA, Foster GD, Bennett A, Steinberg C, Sarwer DB. Obese women's perceptions of their physicians' weight management attitudes and practices. Arch Fam Med 2000;9:854-60.

14. Bardia A, Holtan SG, Slezak JM, Thompson WG. Diagnosis of obesity by primary care physicians and impact on obesity management. Mayo Clin Proc 2007;82:927-32.

15. Jackson JE, Doescher MP, Saver BG, Hart LG. Trends in professional advice to lose weight among obese adults, 1994 to 2000. J Gen Intern Med 2005; 20:814-8.

16. Sciamanna CN, Tate DF, Lang W, Wing RR. Who reports receiving advice to lose weight? Results from a multistate survey. Arch Int Med 2000;160:2334-9.

17. Potter MB, Vu JD, Croughan-Minihane M. Weight management: what patients want from their primary care physicians. J Fam Pract 2001;50:513-8.

18. Loureiro ML, Nayga RM. Obesity, weight loss, and physician's advice. Soc Sci Med 2006;62:2458-68.

19. Davis NJ, Emerenini A, Wylie-Rosett J. Obesity management: physician practice patterns and patient preference. Diabetes Educ 2006;32:557-61.

20. Flocke SA, Clark A, Schlessman K, Pomiecko G. Exercise, diet, and weight loss advice in the family medicine outpatient setting. Fam Med 2005;37:41521.

21. Stevens VJ, Obarzanek E, Cook NR, et al. Longterm weight loss and changes in blood pressure: results of the Trials of Hypertension Prevention, phase II. Ann Intern Med 2001;134:1-11.

22. Appel LJ, Champagne CM, Harsha DW, et al. Effects of comprehensive lifestyle modification on blood pressure control: main results of the PREMIER clinical trial. JAMA 2003;289:2083-93.

23. Knowler WC, Barett-Connor E, Fowler SE, et al. Reduction in the incidence of type 2 diabetes with lifestyle intervention or metformin. N Engl J Med 2002;346:393.

24. Murray DM, Varnell SP, Biltstein JL. Design and analysis of group-randomized trials: A review of recent methodological developments. Am J Pub Health 2004;94:423-32.

25. Parker DR, Evangelou E, Eaton CB. Intraclass correlation coefficients for cluster randomized trials in primary care: the Cholesterol Education and Research Trial (CEART). Contemp Clin Trials 2005; 26:260.

26. Taira DA, Safran DG, Seto TB, Rogers WH, Tarlov AR. The relationship between patient income and physician discussion of health risk behaviors. JAMA 1997;278:1412-7.

27. Eaton CB, Goodwin MA, Stange KS. Direct observation of nutrition counseling in community family practice. Am J Prev Med 2002;23:174-9.

28. Janssen I, Heymsfield SB, Allison DB, Kotler DP, Ross R. Body mass index and waist circumference independently contribute to the prediction of nonabdominal, abdominal, subcutaneous, and visceral fat. Am J Clin Nutr 2002;75:683-8.

29. Mellen PB, Palla SL, Goff DC, Bonds DE. Prevalence of nutrition and exercise counseling for patients with hypertension, united states, 1999 to 2000. J Gen Intern Med 2004;19:917-24.

30. Greiner KA, Born W, Hall S, Hou Q, Kimminau KS, Ahluwalia JS. Discussing weight with obese primary care patients: physician and patient perspectives. J Gen Intern Med 2008;23:581-7.

31. Pollak KI, Ostbye T, Alexander SC, et al. Empathy goes a long way in weight loss discussions. J Fam Pract 2007;56:1031-6.

32. Hiddink GJ, Hautvast JG, van Woerkum CM, Fieren CJ, van't Hof MA. Nutrition guidance by pri- 
mary-care physicians: perceived barriers and low involvement. Eur J Clin Nutr 1995;49:842-51.

33. Kushner RF. Barriers to providing nutrition counseling by physicians: a survey of primary care practitioners. Prev Med 1995;24:546-52.

34. Park ER, Wolfe TJ, Gokhale M, Winickoff JP, Rigotti NA. Perceived preparedness to provide preventive counseling: reports of graduating primary care residents at academic health centers. J Gen Intern Med 2005;20:386-91.

35. Foster GD, Wadden TA, Makris AP, et al. Primary care physicians' attitudes about obesity and its treatment. Obes Res 2003;11:1168-77.

36. Bordowitz R, Morland K, Reich D. The use of an electronic medical record to improve documentation and treatment of obesity. Fam Med 2007;39:274-9.

37. Woolf SH, Krist AH, Johnson RE, et al. A practicesponsored web site to help patients pursue healthy behaviors: an ACORN study. Ann Fam Med 2006; $4: 148-52$.
38. Hassol A, Walker JM, Kidder D, et al. Patient experiences and attitudes about access to a patient electronic health care record and linked web messaging. J Am Med Inform Assoc 2004;11:505-13.

39. Barud S, Marcy T, Armor B, Chonlahan J, Beach P. Development and implementation of group medical visits at a family medicine center. Am J Health Syst Pharm 2006;63:1448-52.

40. Miller D, Zantop V, Hammer H, Faust S, Grumbach K. Group medical visits for low-income women with chronic disease: a feasability study. J Womens Health 2004;13:217-25.

41. Bodenheimer T. Transforming practice. N Engl J Med 2008;359:2086-9.

42. Fiscella K, Epstein RM. So much to do, so little time: care for the socially disadvantaged and the 15-minute visit. Arch Intern Med 2008;168:184352. 